\title{
EVOLUCIÓN HISTÓRICA DE LA ORALIDAD Y LA ESCRITURA EN EL PROCESO CIVIL ESPAÑOL Y ECUATORIANO
}

ORAL AND WRITTEN PROCESS HISTORIC EVOLUTION ON SPAIN AND ECUADOR

\section{Álvaro R. Mejía Salazar*}

Resumen: El Ecuador enfrenta el mayor reto en la historia de su administración de justicia no penal: la implementación del sistema de juzgamiento por audiencias. Más allá del debate respecto a las debilidades que dicha implementación experimenta en la práctica, conviene realizar una visión retrospectiva sobre la historia de la escritura y la oralidad en los procesos. A tales efectos, se estudiará la evolución de estas formas de comunicación de los actos procesales partiendo de la edad antigua, pasando por la medieval, hasta llegar a la colonial, republicana y contemporánea del Ecuador. Todo esto nos llevará a comprender de mejor manera a cada modelo de comunicación de los actos procesales y confirmar la conveniencia de la oralidad, al menos, en lo que al proceso civil se refiere. Este ensayo, realizado bajo un método histórico, de manera cronológica, abarcará un período comprendido entre las sociedades primitivas y la puesta en vigencia del COGEP.

Palabras clave: Reforma procesal, derecho procesal, proceso oral, historia del derecho, Ecuador

\footnotetext{
* Abogado y licenciado en Jurisprudencia, Pontificia Universidad Católica del Ecuador, Quito. Magíster en Derecho y especialista superior en Tributación, Universidad Andina Simón Bolívar, Sede Ecuador. Doctorando en Derecho, Universidad Complutense de Madrid, España. Docente de la Pontificia Universidad Católica del Ecuador, Quito, y de la Universidad Andina Simón Bolívar, Sede Ecuador. Condecoración Aurelio Espinosa Pólit (2015), por el I. Municipio de San Francisco de Quito, en atención a sus aportes a la literatura jurídica nacional. Autor de Los recursos administrativos, Diccionario de Derecho Tributario, Los medios de impugnación ante el proceso contemporáneo y de múltiples ensayos jurídicos. armejiasalazar@gmail.com
} 
Abstract: Ecuador faces its greatest challenge in the history of its noncriminal justice administration: the implementation of the judgment by hearing process. Beyond the debate regarding the weaknesses that, in practice, this implementation experiences, it is convenient to make a retrospective review of the history of writing and orality in the processes. To these effects, the evolution of these forms of communication of the procedural acts will be studied; starting from the old age, through the medieval times, to the colonial, republican and contemporary times of the Ecuador. This will lead us to better understand each method of communication of procedural acts and will confirm the convenience of the oral technique - at least as far as the civil process is concerned. The study follow an historic method that analyze all periods of procedural evolution chronologically. This essay will cover a period between primitive societies and the COGEP (the current non-criminal procedural code).

Keywords: Procedural Reform, Procedural Law, Oral Procedure, History of Law, Ecuador

Sumario. I. Introducción. II. Historia antigua. II. Proceso en la edad media. III. Proceso español. IV. La oralidad en el Ecuador. V. Conclusiones. Referencias.

\section{INTRODUCCIÓN}

A lo largo de la historia, muchos pensadores han tratado de explicar las complejidades del ser humano. La libertad y la sociabilidad de la persona han sido temas de principal interés para filósofos como Aristóteles y Rousseau — pilares del pensamiento sociopolítico occidental-. En su Política, Aristóteles desarrolló la teoría del zoon politikon, la cual defiende la naturaleza política de los seres humanos como explicación de la existencia de las sociedades ${ }^{1}$. Por su parte, Juan Jacobo Rousseau en su obra El contrato social ${ }^{2}$, ponderó a la libertad absoluta del ser humano como su valor más connatural y entendió que la convivencia social —en la cual no se puede ejercer una libertad absoluta - es fruto de un pacto celebrado en algún momento remoto de la historia, en virtud del cual, los hombres y mujeres decidieron ceder parte de sus libertades a un ser ficticio —el Estado - el cual estaría encargado de administrar dichas libertades con el fin de tutelar derechos de los partícipes del pacto, así como de

\footnotetext{
${ }^{1}$ Cfr. Aristóteles, Política, 2011.

${ }^{2}$ Cfr. Rousseau, El Pacto Social, 2001.
} 
organizar y garantizar el correcto funcionamiento y desarrollo de la convivencia grupal ${ }^{3}$.

Es así que uno de los fines que debe precautelar el Estado como administrador y protector de la sociedad es la paz social y esto ha sido una constante a lo largo de la historia humana, pues aún en aquellas sociedades arcaicas donde no existió la idea de un Estado sino únicamente la de un líder grupal, fue común que a éste se le encargase la resolución de las controversias entre los miembros del grupo que lideraba (primitiva administración de justicia heterocompositiva) ${ }^{4}$.

\section{HistoriA ANTIGUA}

De esto partimos para señalar que en su origen el proceso fue oral, pues en las sociedades primitivas, donde de hecho ya se ventilaban controversias ante un tercero decisor, no se había desarrollado la escritura o esta no era de acceso al común de las personas. En la Grecia clásica apreciamos de manera clara como los litigantes fueron forzados por la presión de la opinión pública, así como por el acrecentamiento del poder de los gobernantes, a abstenerse de la lucha armada o de la venganza de la sangre y a buscar la decisión de los sabios ancianos que, en virtud de su preponderancia social o personal, estaban predestinados a actuar como árbitros. De hecho, el arbitraje llegaría con el tiempo a adoptar la condición de obligatorio en Grecia y pasaría de ser un método privado de solución de conflictos a uno administrado por el Estado en calidad de cosa pública, según lo señala Hans Julius Wolff (2007, pp. 336 y 340). Este autor nos recuerda que en Grecia el proceso fue netamente oral, según lo demuestran relatos de aquella época, entre ellos los homéricos ${ }^{5}$. Si bien existen dudas sobre la conformación de los tribunales de ancianos y el jurado — sistema también desarrollado en Grecia-, lo que no cabe duda es que el proceso griego de la época clásica fue oral, sobre la base de alegaciones y pruebas presentadas por el litigante en el ágora ante los decisores quienes

\footnotetext{
${ }^{3}$ La teoría rousseauniana del surgimiento de la sociedad y del Estado es la que en nuestro criterio mejor se identifica con la manera en que comprendemos a estos dos conceptos, si bien otras teorías sobre el surgimiento del Estado, como por ejemplo la teoría del imperio de la fuerza, bien pueda que se acerquen más a la realidad histórica. Sobre la teoría del imperio de la fuerza, cfr. Rojina, 1968, p. 124.

${ }^{4}$ Debemos considerar que los medios autocompositivos de solución de conflictos, si bien resultan ser los más remotos en la historia humana, fueron cayendo en desuso en la medida en que la vida comunitaria se iba desarrollando.

${ }^{5}$ Se refiere los versos del 497 al 508 del Libro XVII de la Ilíada, donde Homero escribe sobre la secuencia de imágenes constantes en el legendario escudo de Aquiles.
} 
apreciaban de forma directa las posiciones litigiosas y resolvían el caso (cfr. Wolff, 2007, pp. 344, 350-356).

En Roma el proceso fue inicialmente privado, pues se basaba en un convenio al que arribaban las partes para someter el conflicto a la resolución de un juez privado (arbiter ex compromisso). Un segundo momento, el de la época republicana, se dio cuando el Estado romano decidió que los litigios privados debían someterse a unos árbitros autorizados estatalmente (iudex). Nació de esta manera el proceso romano de ciudadanos ${ }^{6}$, el cual se dividía en dos etapas: la primera denominada in iurie se encontraba dirigida por un pretor, funcionario ante quien se determinaba los hechos y los términos de la controversia, se buscaba además apercibir al demandado respecto del eventual litigio (cfr. Vescovi, 1984, pp. 25 y 26). La etapa in iuirie se iniciaba con la editio actionis en la cual el demandante exponía sus pretensiones al pretor en presencia del demandado. En un inicio esta exposición era oral, bajo las fórmulas de las legis actionis, pero con el tiempo se tornó en un formulismo escrito. El demandado debía proceder con la litis contestatio a fin de presentar su postura frente a lo argumentado por el demandante. El pretor analizaba las pretensiones y ciertas cuestiones previas - lo que hoy llamaríamos presupuestos procesales - y de encontrar procedente el caso lo remitía a un juez para que lo conociera y resolviera. Arribados a esta etapa el juez, a través de audiencias, escuchaba a las alegaciones de las partes y atendía las pruebas que le pudieren presentar, apud iudicem. En atención a esto, Leandro Prieto-Castro considera que el proceso romano de esta época observó plenamente la forma oral, así como los principios de inmediación y publicidad (cfr. Prieto-Castro y Ferrándiz, 1968, pp. 264-266).

Un tercer momento en la evolución procesal romana, que coincide con el principado o época imperial, denota el nacimiento del proceso escrito (extraordinaria cognitio). En esta etapa se acentuó el carácter de público del proceso, en cuanto a materia de exclusiva organización y administración estatal; desaparecieron las dos fases, pues todo se desarrollaba sin interrupción ante el juez; el documentar los actos judiciales se volvió una práctica obligatoria, con lo cual tomó protagonismo el expediente físico; y, los actos procesales fueron desconcentrándose más y más. Es así que la oralidad y la publicidad dieron paso a la escritura y al secreto, acaso también por el aparecimiento de mayor número de causas y de institutos y negocios jurídicos más complejos (cfr. Vescovi, 1984, p. 267).

\footnotetext{
${ }^{6}$ Recordemos que las controversias entre no ciudadanos romanos eran resueltas por el pretor peregrino, el cual poseía imperium y resolvía dentro de un proceso oral.
} 
Respecto del proceso germano - barbárico - el autor teutón James Goldschmidt informa que fue oral, público y formalista; lo primero por la ausencia de escritura entre los pueblos germanos y lo último, por lo incierto del derecho material. El proceso se lo realizaba a través de debates ante la asamblea de los miembros libres del pueblo, quienes ostentaban la jurisdicción. Existía un funcionario cercano a lo que hoy consideramos juez, pero únicamente actuaba como un investigador del Derecho y como un director del debate. El proceso, acorde a Goldschmidt, se desarrollaba de la siguiente manera: el actor solicitaba la citación del demandado, para que este acudiese ante la asamblea, donde se exponía verbalmente la demanda y la contestación, iniciándose de esta forma el debate procesal. En la misma comparecencia se actuaban las pruebas testimoniales sobre la «idoneidad y ausencia de tacha» de las partes e incluso, la aplicación de ordalías (pruebas del agua caliente, del fuego, del hierro candente, entre otras). La asamblea decidiría sobre el derecho y sobre a quién corresponde cada cosa; esta resolución debía concretarse en una especie de contrato entre los litigantes, contrato que devenía en la real fuente de las obligaciones, pues la resolución no poseía tal fuerza vinculante (cfr. Goldschmidt, 1936, pp. 12-15).

\section{Proceso EN LA EDAD MEDIA}

Avanzando en el tiempo y habiendo revisado los procesos romanos y germanos, arribamos a la caída del imperio latino occidental en manos de los teutones. Esta circunstancia evidentemente generó un cambio social, político y jurídico en la otrora Hispaniae provinciae Romanae, conquistada principalmente por huestes visigodas. $\mathrm{Si}$ bien el derecho romano vulgarizado se mantuvo rigiendo de facto la vida en la península ${ }^{7}$, también se produjeron inevitables e importantes aportaciones de la cultura jurídica visigoda. Esto lo demuestra la Lex Visigothorum —siglo VIIrecopilación de leyes atribuida al monarca Recesvinto y que perduraría siglos, devenida en el Liber Iudiciorum y luego en el Fuero Juzgo. El proceso previsto por esta legislación ${ }^{8}$ presenta a un juez funcionario público, estable y asalariado, susceptible de recusación y responsable por daños que pudiera causar su ignorancia y por actos de corrupción en los que estuviera involucrado — cohecho- . Respecto a las partes procesales se buscó garantizar su igualdad en el proceso. En lo que a nuestra materia

\footnotetext{
${ }^{7}$ De hecho, en Roma el proceso se mantuvo casi sin modificaciones en temas privados, aún bajo el dominio bárbaro. Cfr. Rocco, 1959, p. 162.

${ }^{8}$ Cfr. Fuero Juzgo, Título II, Libro I (1815).
} 
de estudio se refiere, el proceso fue oral y público, con comunicación directa entre las partes. En efecto, realizada la citación al demandado, los litigantes comparecían ante el juez, quien escuchaba al demandante y al demandado, las pruebas de cada parte - consistentes en documentos, de haberlos, testigos y juramentos-, luego de lo cual el juez resolvía el caso. $\mathrm{Su}$ sentencia podía ser apelada ante un superior, si existía, o de no directamente al rey. Cabe señalar que la celeridad procesal fue un tema de preocupación y expreso tratamiento esta legislación, una de cuyas normas disponía: «no debe ser prolongado mucho el pleito... y mayormente si el que se querella es pobre (...)» (Prieto-Castro y Ferrándiz, 1968, pp. 268269). Según apreciamos, el proceso visigodo hispano conservó institutos romanos, como el juez funcionario público, y también elementos orgánicos del proceso germano, como proceso oral, dando como resultado un útil medio para la solución de controversias que estuvo largos siglos al servicio del pueblo ibérico.

La edad media trajo consigo varios cambios sociales y consecuentemente jurídicos. El feudalismo y la proliferación de señoríos comportaron que la jurisdicción pasase a ser atributo de los señores feudales territoriales y que se desarrollasen procesos jurisdiccionales propios de cada señorío; no obstante, en la generalidad de los casos la oralidad continuaba siendo la tónica dominante durante esta época (cfr. Goldschmidt, 1936, p. 17). Para esta época, el cristianismo había generado una sociedad teocéntrica en Europa, con influencia en el mundo jurídico procesal. En este ambiente surgió el así llamado proceso de inspiración romano-canónica caracterizado por la escritura con fases cerradas y preclusivas, así como secretas (cfr. Vescovi, 1984, p. 32). Fue el papa Inocencio III quien decretó que todo acto procesal debía constar por escrito y que el juez no podía juzgar sino sobre esa base (cfr. Rúa, 1991, p. 101). Interesante es conocer que en esta época el demandado podía presentar tanto excepciones previas como de fondo; las previas debían ser resueltas de manera anticipada a la resolución del caso, esto es, a la resolución de las pretensiones y de las excepciones de fondo (cfr. Vescovi, 1984, p. 32). No obstante, este proceso escrito trajo consigo una serie de inconvenientes relativos a la tardanza de la resolución de los juicios, razón por la cual se buscó un nuevo proceso más ágil, originándose de esta forma el sommario, habiendo sido su principal impulsador el papa Clemente V, a través de su célebre bula Clementina Saepe. En este tipo de proceso se procedía simpliceter et de plano ac sine strepitu et figura iudici, es decir, toda la discusión procesal se concentraba en una audiencia, estableciéndose la oralidad del juicio, aumentándose los poderes y la iniciativa del juez en la dirección del proceso (cfr. Rocco, 1959, p. 165). 


\section{PROCESO ESPAÑOL}

De regreso a España, con el aparecimiento de Alfonso $\mathrm{X}$ nace un nuevo cuerpo normativo que contuvo reglas procesales, tras seis siglos de paro. La III Partida prevé las normas sobre juicios ${ }^{9}$, las cuales comportan un cambio total con el proceso hasta entonces vigente ${ }^{10}$; mucho tuvo que ver en aquellos cambios el descubrimiento del llamado Código de Justiniano y la difusión que los glosadores boloñeses dieron al tema. Es así como las leyes alfonsinas generan nuevas formas procesales, produciendo un cambio del propio sistema con el abandono de lo oral por lo escrito (cfr. Panateri, 2013, p. 268). En más, Prieto-Castro (1958, pp. 268-269) sostiene que los distintos cuerpos normativos que se fueron sucediendo ${ }^{11}$ no aportaron cambios fundamentales en la estructura de proceso.

Los territorios ultramarinos de España, entre los cuales se encontraba la Real Audiencia de Quito, se regían por las mismas leyes vigentes en la península, salvo lo que hacía relación con temas comerciales y migratorios, los cuales poseían una regulación distinta. En materia procesal, la aplicación de los fueros, ordenanzas y las posteriores recopilaciones era diaria ante el tribunal de justicia doméstico - Real Audiencia cuya sede se encontraba en Quito, como hemos anotado - ante el juzgador de alzada - el virrey de Lima o de Santa Fe, según la época - o ante la metrópoli, en aquellos casos en que, a través de recursos o en razón de los fueros de los querellantes, los procesos debían ser tramitados en la península. En los territorios de la Real Audiencia de Quito vivieron numerosos titulados a fuero de Castilla e incluso un Grande de España (cfr. Guzmán, 1957).

Arribados ya al siglo XIX, además de algunas normas orgánicas relacionadas con el poder judicial, como el Reglamento Provisional para la Administración de Justicia, en España se emitió Ley de Reguladora del Juicio de Menor Cuantía (1838), la cual contenía un proceso para el juzgamiento de litigios de montos menores, que estuvo inspirado en los principios de oralidad, concentración, inmediación, impulso de oficio y plazos improrrogables. No obstante, esta ley fue prontamente sustituida por la que fuera la primera Ley de Enjuiciamiento Civil emitida en España. En efecto, en 1855 las Cortes aprobaron una ley denominada «para la reforma

\footnotetext{
${ }^{9}$ Cfr. Alfonso X, Las Siete Partidas, 1985, pp. 2 y ss.

${ }^{10}$ Como anotamos párrafos atrás, antes de las Partidas se encontraba vigente el Fuero Juzgo, fiel heredero del Liber Iudiciorum y más remotamente de la Lex Visigothorum; por ello hemos señalado que Las Partidas trajeron la primera reforma normativa en seis siglos. 11 Cfr. Ordenamiento de Alcalá, 1348; Ordenanzas de Medina, 1489; Ordenanzas de Alcalá, 1503; Leyes de Toro, 1503; Nueva Recopilación, 1567; Novísima Recopilación de las Leyes de España, 1805, entre otros.
} 
de los procedimientos en los juicios civiles», la cual pretendió refundir la normativa existente y emitir un cuerpo legal único, sólido y coherente. La Ley de Enjuiciamiento Civil de 1855 consagró el principio dispositivo para el proceso y la escritura como base indiscutible del actuar procesal ${ }^{12}$. Como bien señala Juan Montero Aroca, opinando sobre el protagonismo de la escritura en el proceso de la Ley de 1855: «El brocardo quod non est in actis non est in mundo reflejaba exactamente la concepción de que el juez, para dictar sentencia, sólo podía tomar como base aquello que se encontraba documentado» (Montero Aroca, 2001, p. 36). La prueba atendía al secreto, pues en su práctica no se admitía ni la publicidad general ni la presencia de la parte contraria en las pruebas de confesión o testifical, con lo que se limitaba el principio de contradicción (p. 37).

Para 1868, la desaparición del proceso mercantil con el Decreto de Unificación de Fueros de 1868, supuso la necesidad de hacer una nueva ley procesal civil. Es así que se emitió la nueva Ley de Enjuiciamiento Civil (en adelante LEC) mediante Real Decreto de 3 de febrero de 1881. Esta ley, mantuvo la escritura y el formalismo para el proceso, pese a que la oralidad era ya considerada por varias jurisdicciones como la forma de comunicación de los actos procesales más adecuada para la tramitación de litigios $^{13}$. Se entiende entonces que autores como Prieto-Castro hayan expresado que el proceso previsto por la LEC 1881 mantuviese:

«un apego absurdamente exagerado a la tradición, que en materia procesal no es admisible como material exclusivo de trabajo, ha hecho que nuestra L.E.C. sea una resurrección del Derecho canónico para el siglo XX» (Prieto-Castro y Ferrándiz, 1968, p. 269).

\section{O como Montero Aroca (2001) que señaló que:}

«la Ley de 1881 no lleva realmente en vigor más de cien años, sino que tenemos un proceso del que deban buscarse sus orígenes en el siglo XIII (...). La LEC de 1881 supuso la traducción al castellano moderno de la mayor parte de instituciones ya conocidas en Las Partidas y respecto de las que muy poco se había alterado en los últimos siete siglos».

Recordaremos, según lo hemos anotado en párrafos precedentes, que fueron las leyes alfonsinas de las primeras que abandonaron la oralidad procesal y la sustituyeron por la escritura.

\footnotetext{
12 Desde entonces y sólo hasta el año 2000, las Leyes de Enjuiciamiento Civil españolas consagraron un sistema procesal civil basado en la escritura.

${ }^{13}$ Recordemos que en Francia el proceso era principalmente oral. Alemania implementó la oralidad al proceso con el Código de Hannover de 1850 y con la Ordenanza alemana de 1877.
} 
Mientras esto ocurría en España, en Austria-Hungría se desarrollaba un hito determinante en la historia de la oralidad en el proceso civil. Según señalamos, en Alemania se había emitido el 30 de enero de 1877 la Ordenanza Procesal Civil (Zivilprozessordnung) ${ }^{14}$ que instituyó un proceso oral a través de una audiencia en la que se tramitaban y resolvían tanto los temas previos e incidentales, cuanto los temas de fondo (cfr. Alsina, 1941, p. 95-97). Este modelo ultra concentrado trajo consigo varios inconvenientes sobre todo con el juzgamiento de casos complejos. Considerando esta circunstancia, el ministro de justicia austríaco y profesor de la universidad de Viena, Franz Klein, concibió un nuevo proceso para implementarlo en el imperio austro-húngaro. El proceso era oral, al igual que el alemán, pero no se formaba de una única audiencia, sino de dos: una preliminar, destinada a seleccionar la materia de la causa y a resolver las cuestiones previas que pudiesen ser planteadas por las partes; y, una audiencia de juzgamiento, la cual se llevaba a cabo sólo si se superaba la preliminar. En la audiencia de juzgamiento se conocían y resolvían únicamente los temas de fondo, lo cual permitía a las partes y sobre todo al juzgador, el concentrarse en la materia litigiosa principal y resolver sobre el fondo (cfr. Chiovenda, 2005, p. 139). El proceso desarrollado por Klein se constituyó en el modelo de la oralidad europea continental.

Regresando a España, durante todo el siglo XX muchos fueron los autores que insistían sobre la necesidad de una reforma procesal que implementara la oralidad para el juzgamiento de la materia civil. Uno de los principales fue Víctor Fairen, quien posee una larga bibliografía sobre estos temas, publicada sobre todo a mediados del siglo pasado. La tendencia procesal por la oralidad fue recogida por primera vez en España en su carta magna de 1978. En su título VI, que trata sobre el poder judicial, consta el art. 120.2 que expresamente dispone: «El procedimiento será predominantemente oral, sobre todo en materia criminal». La redacción de esta norma constitucional ha concitado varios reparos, desde quienes la observan por ambigua para tratarse de un contenido constitucional, pasando por quienes la consideran como "inoportuna", hasta quienes la califican como un "reglamentarismo" (Palomo, 2005, p. 24).

Más allá de todos los reparos, se considera que la voluntad del constituyente fue exigir que los procedimientos judiciales estuviesen presididos por la oralidad, como ya sucedía hasta ese momento en los

\footnotetext{
${ }^{14}$ Ya antes, en 1850, se había emitido el Código de Hannover, que implementó un proceso oral exacerbado, pues según tal normativa sólo los actos cumplidos oralmente tenían validez y los actos escritos eran considerados como jurídicamente inexistentes. Rúa, 1991, 106-107.
} 
ámbitos de la justicia penal y laboral (cfr. Picó i Junoy, rec. 2013, p. 1; Vázquez Sotelo, rec. 2013, p. 2), entendiéndose que el procedimiento oral es el que mejor responde a las necesidades de la administración de justicia, como medio para la garantía y protección de los derechos de las personas.

En 1985 aparecía la Ley Orgánica del Poder Judicial, cuerpo normativo que contuvo mandatos relacionados con la oralidad, aun cuando la redacción de los mismos fue similar a la de la CEsp y, por tanto, mereció similares reparos. En efecto, si bien en el noveno de sus motivos se expresa que «la Constitución exige y esta Ley Orgánica consagra los principios de oralidad y publicidad, para lo que se acentúa la necesaria inmediación que ha de desarrollarse en las leyes procesales», en el Título III "De las actuaciones judiciales", Capítulo I "De la oralidad, publicidad y lengua oficial", la manera en que esta Ley consagra el "principio" de oralidad es la siguiente: «las actuaciones judiciales serán predominantemente orales, sobre todo en materia criminal, sin perjuicio de su documentación» (art. 229.1). De allí que Andrés de la Oliva Santos señale: «Durante mucho tiempo, este precepto constitucional — de oportunidad discutible — solo ha tenido el reflejo - que no un genuino desarrollo- en la norma del art. 229.1 LOPJ, casi un mero calco del precepto constitucional» (Oliva Santos, 2012, p. 230).

Es así que, durante casi un cuarto de siglo a partir de la expedición de la CEsp, el proceso civil español se mantuvo regido por la LEC 1881 y por la forma procedimental escrita que tal normativa consagraba. Existieron, no obstante, algunos intentos por reformar el sistema procesal civil, no solo con miras a introducir la oralidad, sino también a dar solución a múltiples problemas de que adolecía la administración de justicia desde la perspectiva del proceso, entre ellos la Ley de Bases del Anteproyecto del Código Procesal Civil de 1966, la propuesta de Corrección y Actualización de la ley de Enjuiciamiento Civil de 1970; la aprobación de la Ley 34/1984 de 6 de agosto, de reforma procesal, o el Borrador de Anteproyecto de la nueva LEC de 1995 (cfr. Barona Vilar, 2002).

Fue solo en el año 2000 cuando se concretaron los esfuerzos por implementar la oralidad para el contencioso civil. Es así que, tras superar las fases legislativas correspondientes, la nueva LEC se publicó en el BOE $\mathrm{n}^{\circ} 7$, de 8 de enero. Esta Ley tuvo por enseña el implementar regulaciones articuladas y coherentes, innovaciones y cambios sustanciales para la efectividad, con plenas garantías, de la tutela que se confía a la Jurisdicción civil. De hecho, respecto a la LEC 1881 y a las reformas que a lo largo del tiempo se le realizaron, la vigente LEC constituyó un cambio cualitativo muy importante. 
En lo que se refiere al modelo procesal, el fundamento ideológico de la LEC es liberal, de allí que se inspira:

«en el principio de justicia rogada o principio dispositivo, del que se extraen todas sus razonables consecuencias, con la vista puesta, no solo en que, como regla, los procesos civiles persiguen la tutela de derechos e intereses legítimos de determinados sujetos jurídicos, a los que corresponde la iniciativa procesal y la configuración del objeto del proceso, sino en que las cargas procesales atribuidas a estos sujetos y su lógica diligencia para obtener la tutela judicial que piden, pueden y deben configurar razonablemente el trabajo del órgano jurisdiccional, en beneficio de todos» (LEC, exposición de motivos, IV $)^{15}$.

El principio de audiencia o contradicción se encuentra, así mismo, plenamente garantizado por este cuerpo legal.

En cuanto al modelo procedimental, la LEC busca «la real simplificación procedimental» (LEC, exposición de motivos, VI) y, por ello, eligió la oralidad, que ciertamente estaba ya ordenada por la Constitución. Consideramos más importante, no obstante, que la LEC no se limitó a la mera implementación de la forma procedimental, sino que optó expresamente por la observancia y concreción de los principios procedimentales. Así, en el número XII de la exposición de motivos se prevé:

«La Ley diseña los procesos declarativos de modo que la inmediación, la publicidad y la oralidad hayan de ser efectivas. En los juicios verbales, por la trascendencia de la vista; en el ordinario, porque tras demanda y contestación, los hitos procedimentales más sobresalientes son la audiencia previa al juicio y el juicio mismo, ambos con la inexcusable presencia del juzgador».

\section{LA ORALIDAD EN EL ECUADOR}

Respecto de Ecuador, ni bien constituida la República el 23 de septiembre de 1830 , la producción legislativa fue prolífica. No se abstrajo de esta circunstancia la normativa procesal civil, es así que la primera Ley del Procedimiento Civil fue dictada por el Congreso Constitucional de la República el 8 de noviembre de 1831, sancionada el 16 de noviembre del

\footnotetext{
${ }^{15} \mathrm{El}$ art. 216 contiene la previsión del principio de justicia rogada, disponiendo que «los tribunales civiles decidirán los asuntos en virtud de las aportaciones de hechos, pruebas y pretensiones de las partes, excepto cuando la ley disponga otra cosa en casos especiales». En concordancia, el art. 19 prevé el derecho de disposición de los litigantes, en virtud del cual «los litigantes están facultados para disponer del objeto del juicio y podrán renunciar, desistir del juicio, allanarse, someterse a mediación o a arbitraje y transigir sobre lo que sea objeto del mismo».
} 
mismo año por el presidente Juan José Flores y publicada en el Primer Registro Auténtico Nacional, ${ }^{\circ}$ 28, año de 1831. Según recuerda Vanesa Aguirre Guzmán, en esta ley el órgano legislativo reconoció expresamente que no se trataba de un «código completo sobre el procedimiento civil». La segunda ley procesal civil fue dictada por la Convención del Ecuador el 15 de agosto de 1835, sancionada EL 22 de agosto del mismo año por el presidente Vicente Rocafuerte y publicada en el Primer Registro Auténtico Nacional, $\mathrm{n}^{\circ}$ 5, de ese año, pp. 2-36. A esta ley le siguió la Ley del Procedimiento Civil, de 7 de diciembre de 1848, dictada por el Senado y Cámara de Representantes del Ecuador reunidos en Congreso y sancionada en el gobierno de Vicente Ramón Roca. En 1863 el Senado y Cámara de Diputados del Ecuador reunidos en Congreso, elaboraron una nueva Ley de Procedimiento Civil, la cual fue sancionada por el presidente Gabriel García Moreno el 24 del mismo mes y año ${ }^{16}$.

Llegamos de esta forma a 1869, año en que se buscó solventar los yerros legislativos que la ley adjetiva civil ecuatoriana arrastraba desde $1831^{17}$. Es así que la Convención Nacional de 1869 emitió el Código de Enjuiciamientos en Materia Civil, el cual entró en vigencia a partir del 27 de mayo de 1871 (cfr. Troya, 2002, p. 124). Este código estuvo inspirado tanto en la ley española de 1855 , como en los códigos argentino y peruano, pero mantuvo su buena cuota de originalidad. El Código de Enjuiciamientos en Materia Civil se mantuvo vigente hasta 1938, año en el que se emitió el Código de Procedimiento Civil, norma adjetiva que tras una serie de reformas y codificaciones se mantuvo vigente hasta el 22 de mayo de 2016. El Código de Procedimiento Civil estableció un proceso predominantemente escrito, pero con importantes fases de inmediación donde el debate había que realizarlo de manera oral.

En cuanto a la postura del constituyente ecuatoriano respecto a la oralidad, su opción por esta forma de comunicación de los actos procesales data de 1945. En efecto, el art. 93 de la Constitución de 1945 disponía que «Las leyes procesales propenderán a la simplificación y eficacia de los trámites, adoptando en lo posible el sistema verbal» ${ }^{18}$. En la Constitución

\footnotetext{
${ }^{16}$ Cfr. Aguirre, 2012, pp. 80 y ss.; Colección de leyes y decretos dados por el Congreso Constitucional de 1863, 1864, pp. 65-166; Colección de leyes y decretos de la Convención Nacional, 1862, pp. 105-138.

17 Como señalamos en líneas anteriores, el propio legislador de 1821 reconoció lo deficiente de la ley procesal civil que había emitido, acaso por las premuras propias de la organización de un nuevo Estado. Se nos antoja pensar que este reconocimiento fue realizado por recomendación del jurista Dr. José Fernández-Salvador y López Legendre, quien además presidió la Primera Constituyente ecuatoriana.

${ }^{18}$ Constitución de la República del Ecuador de 1945 (R.O. 228, de 6-III-1945).
}

Ius Humani | v. 6 (2017), p. 84 
de 1967 vuelve a aparecer la oralidad: esta vez el art. 200 disponía que «Las leyes procesales procurarán la simplificación y eficacia de los trámites; adoptarán en lo posible el sistema oral» ${ }^{19}$. El art. 93 de la Constitución de 1979, contuvo una disposición similar a la que acabamos de $\operatorname{citar}^{20}$. El constituyente de 1998, dejando de lado los contenidos sutiles que habían mantenido sus predecesores, optó por el siguiente imperativo en el art. 194:

«La sustanciación de los procesos, que incluye la presentación y contradicción de las pruebas, se llevará a cabo mediante el sistema oral, de acuerdo con los principios: dispositivo, de concentración e inmediación» ${ }^{21}$.

La actual Constitución, vigente desde octubre de 2008, prevé en su art. 86.2.b como una de las garantías jurisdiccionales de las personas, que el procedimiento «será oral en todas sus fases e instancias». En concordancia, el art. 168.6 de la Carta Magna, en calidad de «principio» de la administración de justicia, dispone que «la sustanciación de los procesos en todas las materias, instancias, etapas y diligencias se llevará a cabo mediante el sistema oral, de acuerdo con los principios de concentración, contradicción y dispositivo». Según apreciamos, el constituyente ecuatoriano dispuso la implementación del "sistema oral" de una manera dogmática e irreflexiva, cometiendo tres gravísimos errores a nuestro entender: (i) ordenar que la oralidad se aplique en todas las materias ${ }^{22}$; (ii) ordenar que la oralidad se aplique en todas las etapas y diligencias del proceso; y, (iii) ordenar que la oralidad se aplique en todas las instancias y fases del proceso.

Respecto al primer error, este es el mandato de aplicar la oralidad en todas las materias, el constituyente del 2008 atentó contra el principio de configuración legal del proceso, eliminando la capacidad del legislador ordinario de diseñar los procesos según las necesidades sociales y características de los litigios, en lo que a la forma de comunicación de los actos procesales se refiere. Aun cuando conviniera técnicamente que una materia sea jurisdiccionalmente atendida a través de un trámite escrito o mayoritariamente escrito, no se lo podría prever legalmente sin que ello comporte una inobservancia de la Carta Magna. Es evidente que el constituyente se ha inmiscuido indebidamente en la labor del legislador

\footnotetext{
${ }^{19}$ Constitución de la República del Ecuador de 1967 (R.O. 133, de 25-III-1967).

${ }^{20}$ Constitución de la República del Ecuador de 1979 (R.O. 800, de 27-III-1979).

${ }^{21}$ Constitución Política de la República del Ecuador de 1998 (R.O. 1, de 11-VIII-1998).

${ }^{22}$ La regulación del art. 168.6 de la Constitución ecuatoriana tiene especial relevancia para las materias no penales, laborales y de menores, pues estas últimas ya poseían procedimientos orales específicos en sus contenciosos antes del 2008.
} 
ordinario, coartando la posibilidad de que la sociedad reciba una respuesta legislativa ordinaria y expedita a sus necesidades. Además, el hecho de haberse decantado de manera general por la oralidad, ordenando su imperativa aplicación en todas las materias sin dar oportunidad a que se discrimine en cada caso concreto su conveniencia, nos revela un tratamiento dogmático de esta forma procedimental y demuestra que el constituyente creyó que a través de ella se solucionaría buena parte de los problemas de la administración de justicia, lo cual a nuestro criterio comporta un error de inmensas proporciones.

Respecto al segundo error, el ordenar que "todas" las "etapas" y "diligencias" del proceso sean orales, constituye una aplicación del modelo oral en su dimensión más pura o extrema. Debiendo realizarse de manera verbal todos los actos procesales, la escritura habría quedado constitucionalmente proscrita dentro del proceso. Nuevamente la intromisión del constituyente en competencias propias del legislador ordinario acarrea gravísimas consecuencias. Debemos recordar que no corresponde a una Constitución desarrollar contenidos tan reglamentarios como la elección de un modelo de comunicación procedimental y mucho peor, el establecerlo con carácter general. El constituyente no está en capacidad de interpretar necesidades sociales tan específicas, ni esa es su tarea; el haberla asumido solo lleva al fracaso de establecer en una norma suprema - cuyos contenidos se espera sean lo más atemporales posibleun tema por demás coyuntural. Nuevamente el retiro de las facultades del legislador ordinario respecto al diseño del proceso, no hace sino limitar perniciosamente la debida regulación legal de los temas procesales sobre la base de la interpretación de las necesidades sociales y técnicas. Adicionalmente, el decantarse por un modelo oral en su dimensión extrema y aplicarlo de una manera absoluta a todo el contencioso ecuatoriano es un error inconmensurable. La forma oral pura está lejos de ser recomendable por las desventajas comparativas frente a una forma oral combinada con fases escritas, por lo que haberla convertido en un mandato general es un error muy grave que de aplicárselo llevaría al colapso de la administración de justicia.

Respecto al tercer error, la Constitución ordena que en todas sus instancias y fases el proceso debe ser oral. De allí, que la tramitación del recurso de apelación (segunda instancia) y de casación (fase extraordinaria) debería ser oral y como acabamos de analizar en el párrafo anterior, en todas las etapas y diligencias del trámite. En la generalidad de los casos, no es posible producir pruebas dentro de los recursos antes citados, reduciéndose el debate de los mismos a la exposición escrita de los argumentos de impugnación y contestación, argumentos que son 
estudiados y resueltos por el juzgador. Bajo estos supuestos, ordenar la celebración forzosa de una vista resulta estéril y no hace sino retrasar la emisión de la resolución, y, en ciertos casos, incluso pone en riesgo la calidad de tales providencias. Conectando esto con el error constitucional antes analizado, lo técnico de la impugnación de apelación y sobre todo de casación tornaría prácticamente inviable que se pueda resolver adecuadamente estos recursos sobre la sola base de la exposición verbal de los argumentos de impugnación, sin que se los pueda analizar de forma detenida y contrastada con lo resuelto en la sentencia, más aún si la sentencia tampoco se encontraría reducida a escrito.

La manera en que han sido previstos los mandatos constitucionales respecto de la oralidad procedimental posee graves errores, según acabamos de exponer, mismos que van desde la competencia temática que posee el constituyente, pasando por la comprensión de la naturaleza de sus mandatos, hasta en entendimiento en sí mismo de la oralidad. El legislador ordinario, limitado y ligado como se encuentra por los mandatos constitucionales, se ha visto compelido a aplicarlos - aunque en ciertos casos los ha desatendido - al momento de diseñar la ley adjetiva, cuyo proceso de creación pasamos a reseñar.

La reforma procesal en pos de implementar la oralidad inició un año antes de la emisión de la Constitución del 2008, recordemos que este afán se encontraba constitucionalmente previsto desde 1945. Es así que en enero de 2007, Projusticia ${ }^{23}$ enarboló la iniciativa reformista y encargó al Instituto Ecuatoriano de Derecho Procesal ${ }^{24}$ la redacción de un proyecto de nuevo código de procedimiento civil, el cual fue puesto a conocimiento del público en diciembre de 2007 (cfr. Aguirre, 2012, p. 86).

A los pocos meses, en octubre de 2008 , se puso en vigencia la actual Constitución, en cuyos arts. 86.2.b y 168.6 se volvió a prever el imperativo de la oralidad en los procesos, según hemos apreciado. Considerando que el proyecto elaborado por el Instituto Ecuatoriano de Derecho Procesal

\footnotetext{
23 Unidad pública de coordinación para la reforma de la administración de justicia, originalmente adscrita a la presidencia de la entonces Corte Suprema de Justicia; hoy desaparecida luego de su absorción por el Ministerio de Justicia, Derechos Humanos y Cultos. Decreto Ejecutivo 883 (RO No. 267, de 7 de febrero de 2008).

${ }^{24}$ El Instituto Ecuatoriano de Derecho Procesal, es una organización académica sin ánimo de lucro, cuya finalidad primordial es:
}

«impulsar el estudio, la investigación y difusión del Derecho Procesal ecuatoriano y comparado, a fin de mejorar el conocimiento, el desarrollo conceptual y la práctica profesional de esta rama del Derecho en el ámbito nacional e internacional como medio de contribuir a la realización de la justicia» (Estatuto del Instituto, art. 1). 
tuvo como base la Constitución de 1998, el Ministerio de Justicia, Derechos Humanos y Cultos consideró necesario contar nuevamente con la colaboración de miembros del Instituto, para readecuar el proyecto al nuevo marco constitucional. El documento tomó finalmente la denominación de "Proyecto de Código Procesal Civil" y fue entregado al Ministerio en el 2009 (Aguirre, 2012, p. 87). El Proyecto del Instituto Ecuatoriano de Derecho Procesal pretendió implementar el procedimiento oral respondiendo a la realidad ecuatoriana, sobre la base de la experiencia internacional, tanto legislativa como doctrinal en temas procesales.

En marzo de 2009 se puso en vigencia el Código Orgánico de la Función Judicial, que derogó la Ley Orgánica de la Función Judicial. Este Código, atendiendo el imperativo constitucional, prevé en su art. 18 que las normas procesales consagrarán, entre otros "principios", el de oralidad. No obstante, ni la norma constitucional ni el contenido del propio art. 18 se encuentran desarrollados en este cuerpo normativo, que principalmente se encarga de regular la carrera judicial. Si bien algunas normas que desarrollan teóricamente principios procesales y procedimentales o que regulan las obligaciones de los juzgadores en el despacho de las causas o la conducta de los abogados en el patrocinio, podrían relacionarse con la implementación de la oralidad, tales normas también pueden relacionarse perfectamente con el correcto desempeño de las funciones públicas y de la profesión en procesos escritos ${ }^{25}$. De esta forma, en nuestro criterio, se perdió una importante oportunidad para preparar la reforma procesal en ciernes, pues recordemos que desde lo orgánico se requiere una serie de cambios previos para asegurar su correcta incorporación y operación de la oralidad. Por ejemplo, se pudo haber legislado respecto de las actuaciones judiciales, encaminándolas de manera concreta al procedimiento oral; así también pudieron haberse establecido criterios sobre la carga de trabajo conveniente para los órganos judiciales, lo cual si bien depende de factores externos, conviene se posea una directriz legal al respecto. En definitiva, se pudieron incluir varias normas que no solo organizasen los temas relacionados con la carrera judicial o con desarrollos teóricos, sino también normas prácticas que iniciasen la implementación de la oralidad.

Retomando la ruta histórica de la implementación del procedimiento oral para la materia civil en el Ecuador, durante el año 2011, sin motivo alguno que se haya hecho público, el Ejecutivo decidió abandonar el proyecto del Instituto Ecuatoriano de Derecho Procesal. A través del Consejo de la Judicatura ${ }^{26}$ se decidió contratar al Centro de Estudios de

${ }^{25}$ Todo el capítulo II del título I, así como los arts. 103, 107, 127-128, 130, 149, 330 o 335.

${ }^{26}$ Órgano de administración y gobierno de la función judicial en el Ecuador. 
Justicia de las Américas ${ }^{27}$, con sede en $\mathrm{Chile}^{28}$, para la elaboración de un nuevo proyecto de reforma procesal. El 11 de abril de 2012 el Centro presentó al Consejo de la Judicatura del Ecuador el «proyecto de Código Procesal Unificado», cuyo trabajo fue realizado en un $80 \%$ por chilenos. El objetivo primordial de este proyecto fue el de disminuir la duración de los procesos judiciales en el país y unificar la legislación procesal de las distintas materias no penales, según el mandato constitucional. Tras ciertas observaciones y modificaciones, entre las que se incluyó un cambio de la denominación del documento, el Consejo de la Judicatura presentó al foro ecuatoriano el Proyecto de Código General del Proceso (Bermeo, 2013, p. 5).

Para la difusión y conocimiento de este proyecto, el Consejo de la Judicatura organizó varios eventos dirigidos tanto a jueces y demás funcionarios judiciales, así como a abogados y al público en general. Las críticas a este defectuoso intento normativo no se hicieron esperar desde todos los sectores ${ }^{29}$; tan profundos fueron los yerros de este proyecto que

27 Organización creada en el año 1999, por resolución de la Asamblea General de la Organización de Estados Americanos.

${ }^{28}$ Chile es un país cuya realidad, si bien cercana a la ecuatoriana en ciertos aspectos, es muy distante en otros.

${ }^{29}$ El Instituto Ecuatoriano de Derecho Procesal, en unión con el Área de Derecho de la Universidad Andina Simón Bolívar (Ecuador), realizó una serie de conferencias y conversatorios con el fin de analizar a un nivel académico al denominado "Proyecto de Código General del Proceso". Para estos fines se contó con la presencia y participación de funcionarios del Consejo de la Judicatura, del gobierno (entre ellos el Secretario jurídico de la Presidencia de la República), jueces, docentes universitarios de grado y posgrado y abogados en libre ejercicio. La conclusión general, salvo por la opinión de los representantes del Consejo de la Judicatura, pero sí incluyendo la del Secretario Jurídico de la Presidencia, fue de rechazo al proyecto, dados los muchos y graves defectos de los que adolecía. Entre los más destacables yerros de este documento están: el caer en el descomunal error de considerar que la oralidad tiene como principal objetivo la consecución de la celeridad en los procesos y que su sola implementación garantiza dicho objetivo, cuando conocemos que el procedimiento oral no es una fórmula mágica que soluciona las múltiples circunstancias que generan la lentitud procesal, sin olvidar que la plena observancia de los principios de inmediación y concentración constituyen los objetivos más valorados para la oralidad, antes que la mera aceleración procedimental. Otro grave defecto es que al haber sido elaborado en un $80 \%$ por chilenos, el "Proyecto" no respondía ni al régimen jurídico ecuatoriano ni a la realidad social ecuatoriana, gravísimo error atribuible solo a la entidad contratante, esto es, al Consejo de la Judicatura. Por ejemplo, el tratamiento que procesalmente daba a ciertos institutos sustantivos no correspondía a la manera en que dichos institutos sustantivos se encontraban previstos y comprendidos en la normativa ecuatoriana, además, el lenguaje utilizado no se correspondía ni al lenguaje jurídico comúnmente utilizado en Ecuador ni al lenguaje común que se utiliza en el país; de hecho, el "Proyecto" desbordaba términos y expresiones propios de Chile, de "chilenazgos", como popularmente se los denominó. Además, luego de las primeras críticas, los funcionarios del Consejo de la Judicatura se 
finalmente fue archivado. Sin embargo, el afán por lograr la reforma procesal en Ecuador continúo, la Corte Nacional de Justicia y el Consejo de la Judicatura se encargaron de generar un nuevo proyecto de ley adjetiva común, el cual fue presentado a la Asamblea Nacional el 21 de enero de 2014. Luego del debate legislativo correspondiente ${ }^{30}$, el Código Orgánico General de Procesos (COGEP en adelante) fue aprobado en sesión de 12 de mayo de 2015 y publicado en el Registro Oficial 506, de 22 de mayo de 2015.

Este cuerpo normativo, aplicando el mandato constitucional del art. 168.6, prevé los procedimientos comunes que serán aplicados para el juzgamiento de todas las materias no penales. Sin discriminación alguna respecto de la naturaleza, dinamia y requerimientos propios de las distintas materias, establece procesos que han de ser aplicados de forma prácticamente idéntica sea que se juzgue temas tan disímiles entre sí como civiles, laborales, contencioso administrativo, de familia, contencioso tributarios, de inquilinato, entre otros. De manera expresa, en los escuetísimos considerandos del COGEP se sostiene: «es imperioso armonizar el sistema procesal actual a las normas constitucionales y legales vigentes, a través de un cambio sustancial que propone, bajo el principio de la oralidad, la unificación de todas las materias, excepto la constitucional y penal», particular que es confirmado en el art. 1 del Código el cual dispone que «este Código regula la actividad procesal en todas las materias, excepto la constitucional, electoral y penal, con estricta observancia del debido proceso».

En lo que se refiere al modelo procesal, el COGEP opta por el principio de justicia rogada. Observando el mandato constitucional del art. 168.6, el COGEP aplica un modelo de juzgamiento dispositivo para las materias no penales. Esta opción absoluta y general la consideramos por demás errónea, pues desnaturaliza a varias materias que no pueden ser únicamente informadas por el principio dispositivo en virtud de los bienes jurídicos que protegen. En efecto, la cosa pública o intereses de sensibilidad social no pueden reducirse a un tratamiento judicial dispositivo. Así, la materia tributaria o la de menores no pueden limitarse a la disposición que las partes hagan en sus acciones o contestaciones, deberá existir la potestad del juzgador de tutelar en un caso la adecuada

dieron a la tarea de tratar de arreglar sobre la marcha y como podían las graves falencias que presentaba el proyecto, sin mucho lucimiento en esta tarea.

${ }^{30}$ Que pese a haber contado con importantes aportaciones de juristas y abogados en libre ejercicio, no supo aplicar las múltiples recomendaciones realizadas respecto de las graves falencias del proyecto. 
conformación de la obligación tributaria en el primer caso, y el interés superior del menor en el otro. Por tanto, consideramos que caracterizar exclusivamente con el principio dispositivo a materias como la contencioso administrativa, contencioso tributaria, laboral y de familia no se ajusta al debido juzgamiento que ellas ameritan, donde una conjunción de lo dispositivo con lo oficioso han matizado comúnmente el modelo de juzgamiento de este tipo de materias. En todo caso, en lo que se refiere a la materia civil que es la de nuestro interés a efectos de la presente tesis, resulta adecuada la previsión del principio dispositivo como inspirador del juzgamiento $^{31}$. En lo que hace relación con el principio de contradicción, contenido a efectos procesales expresamente por el art. 168.6 de la Constitución, es garantizado por el COGEP a lo largo de sus disposiciones en relación con las actuaciones procesales, tales como la demanda, la contestación a la misma, las pruebas, las impugnaciones, etc.

En cuanto al modelo procedimental, el COGEP pretende aplicar los mandatos constitucionales del art. 86.2 en sus literales b) y e), los cuales disponen que «el procedimiento será sencillo, rápido y eficaz» y que «no serán aplicables las normas procesales que tiendan a retardar su ágil despacho», así como del art. 169, que ordena que «las normas procesales consagrarán los principios de simplificación, uniformidad, eficacia, inmediación, celeridad y economía procesal». Como medio para lograr estos caros ideales, el legislador tanto constitucional como legal optó por la oralidad. En los exiguos considerandos del COGEP, más allá de meras referencias a la normativa suprema que ha sido citada, no existe una definición de la manera en que se han concebido y afrontado estos temas y sobre todo, respecto de la manera en que serán concretados. Donde encontramos una especie de reflexión — no felizmente lograda - sobre algunos temas procedimentales es en el Informe para primer debate del proyecto de COGEP, elaborado por la Comisión Especializada Permanente de Justicia y Estructura del Estado de la Asamblea Nacional ecuatoriana, donde se señala:

«El proyecto respeta la inmediación procesal, la transparencia, la eficacia, la economía procesal, la celeridad, la igualdad ante la ley, la imparcialidad, la simplificación, la uniformidad; y, principalmente, precautela los derechos $\mathrm{y}$

\footnotetext{
${ }^{31} \mathrm{El}$ art. 5 del COGEP dispone que «corresponde a las partes procesales el impulso del proceso, conforme con el sistema dispositivo». En más, el COGEP observa los postulados del principio en lo que hace relación con la iniciativa procesal de acción y contradicción, así como con las cargas que corresponden a los sujetos para efectivizar sus pretensiones y excepciones. Todo esto nos parece muy consecuente con la naturaleza de la materia civil, dentro del juzgamiento de derechos privados.
} 
garantías constitucionales y procesales. Los operadores de justicia requieren de herramientas eficientes, producto de un profundo análisis normativo, doctrinario y jurisprudencial, para redundar en un pragmatismo jurídico que promueve la cultura protectora de los derechos humanos» (Asamblea Nacional, 2014).

\section{CONCLUSIONES}

Ciertamente de la oralidad en el proceso civil proporciona, en la generalidad de los casos, de mayores beneficios que la escritura. La historia que ha tenido que transcurrir para que el Ecuador implemente este modelo ha sido extensa y consideramos que aún faltan muchísimas páginas más por escribir, pues la implementación forzada, precipitada, anti técnica, prácticamente nula en recursos materiales y, por tanto, irresponsable del juzgamiento por audiencias traerá muchas consecuencias a futuro, ciertamente en desmedro de los usuarios de la administración de justicia. 


\section{REFERENCIAS}

Aguirre Guzmán, V. (2012). Tutela Jurisdiccional del Crédito en Ecuador. Quito: Ediciones Legales.

Alfonso X (1985). Las Siete Partidas, tomo II. Madrid: Boletín General del Estado.

Alsina, H. (1941). Tratado Teórico Práctico de Derecho Procesal Civil y Comercial. Buenos Aires: Compañía Argentina de Editores.

Aristóteles (2011). Política. Madrid: Tecnos.

Asamblea Nacional de la República del Ecuador (2014). Informe del primer debate del COGEP. En http://www.asambleanacional.gob.ec/es/contenido/informe-paraprimer-debate-del-proyecto-de-codigo-organico-0 (recuperado el 29-III-2016).

Barona Vilar, S. (2002). Líneas Generales y Principios Configuradores de la Ley 1/2000, de 7 de Enero, de Enjuiciamiento Civil. Revista de Derecho, 1.

Bermeo, J.E. (2013). Implementación del Procedimiento Oral para Materias no Penales en el Sistema Jurídico Ecuatoriano y el Tratamiento del mismo en el Proyecto de Código General del Proceso. Law Review del Colegio de Jurisprudencia de la Universidad San Francisco de Quito, 1.

Chiovenda, G. (2005), Instituciones de Derecho Procesal Civil. Florida: Valletta.

Fuero Juzgo o Libro de los Jueces (1815). Madrid: Real Academia Española-Imprenta de Ibarra.

Goldschmidt, J. (1936). Derecho Procesal Civil. Madrid: Labor.

Guzmán, J.A. (1957). Títulos nobiliarios en el Ecuador, Madrid: Imprenta del Asilo de Huérfanos del Sagrado Corazón de Jesús.

Montero Aroca, J. (2001). Los Principios Políticos de la Nueva Ley de Enjuiciamiento Civil. Valencia: Tirant lo Blanch.

Montero Aroca, J. La Nueva Ley de Enjuiciamiento Civil. Madrid. En http://www.tirant.com/humanidades/monocnt?daId=1\&patron=01\& (recuperado el 11-VII-2013).

Oliva Santos, A. de la, Díez-Picazo Giménez, I. \& Vegas Torres, J. (2012). Curso de Derecho Procesal Civil, I. Madrid. Editorial Universitaria Ramón Areces.

Palomo Vélez, D. (2005). Tesis Oralidad y Escritura en el Nuevo Modelo Procesal Civil Español. Madrid.

Panateri, D. (2013). La Tortura Judicial en las Siete Partidas de Alfonso X, el Sabio. En Palimpsestos: Escrituras y Reescrituras de las Culturas Antigua y Medieval. Buenos Aires: Universidad del Sur.

Picó i Junoy, J. (2008). El Principio de Oralidad en el Proceso Civil Español. Valencia. Universidad de Valencia-AIDP. En http://www.uv.es/coloquio/coloquio/ informes/ip25esp.pdf (recuperado el 11-I-2017).

Prieto-Castro y Ferrándiz, L. (1968). Derecho Procesal Civil, vol. 1. Madrid: Editorial Revista de Derecho Privado. 
Rocco, U. (1959). Teoría General del Proceso Civil. México DF: Porrúa.

Rojina Villegas, R. (1968), Teoría general del estado. México DF: Fuentes.

Rousseau, J.j. (2001). El Pacto Social. Madrid: Aguilar.

Rúa, F. de la (1991). Teoría General del Proceso. Buenos Aires: Depalma.

Troya Cevallos, A. (2002). Elementos de Derecho Procesal Civil, t. 1. Quito: Pudeleco.

Vázquez Sotelo, J.1. La Oralidad en el Moderno Proceso Civil Español. Implantación y Dificultades de la Oralidad. biblio.juridicas.unam.mx/libros/7/3069/5.pdf (recuperado el 11-VII-2013).

Vescovi, E. (1984). Teoría General del Proceso. Bogotá: Temis.

Wolff, H. J. (2007), El Origen del Proceso entre los Griegos. Revista de la Facultad de Derecho de México, 247.

\section{Normativa:}

Alemania, Código de Hannover de 1850.

Alemania, Ordenanza alemana de 1877.

Constitución de la República del Ecuador (R.O. 449, de 20-X-2008).

Constitución de la República del Ecuador de 1945 (R.O. 228, de 6-III-1945).

Constitución de la República del Ecuador de 1967 (R.O. 133, de 25-III-1967).

Constitución de la República del Ecuador de 1979 (RO No. 800, de 27-III-1979).

Constitución Política de la República del Ecuador de 1998 (R.O. 1 de 11-VIII-1998).

Ecuador (1862). Colección de leyes y decretos de la Convención Nacional. Quito: Imprenta del Gobierno.

Ecuador (1864). Colección de leyes y decretos dados por el Congreso Constitucional de 1863. Quito: Imprenta Nacional.

Ecuador, Código Orgánico de la Función Judicial (R.O. n 544, de 9-III-2009).

Ecuador, Decreto Ejecutivo 883, RO No. 267, de 7 de febrero de 2008.

España, Ley Orgánica del Poder Judicial (BOE núm. 157, de 2-VII-1985).

España, Leyes de Toro, 1503.

España, Novísima Recopilación de las Leyes de España, 1805.

España, Nueva Recopilación, 1567.

España, Ordenamiento de Alcalá, 1348.

España, Ordenanzas de Alcalá, 1503.

España, Ordenanzas de Medina, 1489. 